\title{
Representação de Famílias Constituídas por Casais do Mesmo Sexo: A Posição de Professoras de Ensino Fundamental
}

\author{
Maria Cristina Lopes de Almeida Amazonas ${ }^{1}$ \\ Programa de Pós-Graduação em Psicologia Clínica da Universidade Católica \\ de Pernambuco, Recife, PE, Brasil \\ Luciana Leila Fontes Vieira \\ Programa de Pós-Graduação em Psicologia da Universidade Federal de Pernambuco, \\ Recife, PE, Brasil \\ Marcelo Ferreira Leite \\ Instituto de Desenvolvimento Educacional, Recife, PE, Brasil \\ Instituto Integrado de Apoio a Família, Recife, PE, Brasil \\ Ricardo Delgado Marques de Lima \\ Programa de Pós-Graduação em Psicologia Clínica pela Universidade Católica \\ de Pernambuco, Recife, PE, Brasil
}

\section{Resumo}

O objetivo desta pesquisa foi analisar a representação de professores do Ensino Fundamental de escolas públicas e privadas da cidade do Recife a respeito de famílias cujo casal parental é do mesmo sexo. Foram entrevistadas trinta professoras. Os dados foram submetidos à Análise de Conteúdo. Resultaram dois temas: (a) a representação das professoras acerca de famílias cujo casal parental é do mesmo sexo; (b) suas percepções sobre as crianças que vivem neste tipo de família. Predominou um discurso que considera que este tipo de família não é "normal", mas, ainda assim, é preciso respeitá-la. Quanto às crianças, a maioria das professoras afirmou que elas sofrem ou podem sofrer consequências nefastas, tais como: serem vítimas de preconceitos e apresentarem problemas com a futura orientação sexual. Embora uma minoria, há professoras que não veem razão para que essas crianças sofram danos diferentes daqueles que podem ser sofridos por outras que vivem em famílias de configurações tradicionais.

Palavras-chave: Professoras de ensino fundamental, representação de família, casais do mesmo sexo.

\section{Representations of Same-Sex Couple Families: A Perspective from Elementary School Female Teachers}

\begin{abstract}
The aim of this paper was to analyze the representation of families formed by a same-sex couple in the city of Recife by public and private elementary school teachers. Thirty teachers participated in this research. Data were submitted to Content Analysis. Two themes have come out as results: (a) Teachers' representation on families formed by same-sex couples; (b) Their impression on children living in such

Endereço para correspondência: Estrada do Encanamento, 608, Apto. 1303, Casa Forte, Recife, PE, Brasil 52070-000. Fone: 3034-6030. E-mail: crisamaz@gmail.com, lufontesvieira@hotmail.com, marcelofl75@ gmail.com e ricardomarques_psi@yahoo.com.br

Agência de financiamento: Conselho Nacional de Desenvolvimento Científico e Tecnológico (CNPq).
\end{abstract}


families. Predominant discourse oscillated between admitting such families as not "normal" and stating that yet they have to be respected. Regarding the children, most teachers considered that they suffer or may suffer adversity consequences, for instance, as being victims of prejudice or having problems with their sexual orientation. However, there is a small number of teachers who does not see any reason for these children to suffer any different damage than those suffered by the children of any other traditional configuration family.

Keywords: Elementary school female teachers, representation of families, same-sex couples.

\section{Representación de Familias Formadas por Parejas del Mismo Sexo: La Posición de Profesoras de Escuela Elemental}

\section{Resumen}

El objetivo en este estudio fue analizar la representación de maestras de primaria de las escuelas públicas y privadas de la ciudad de Recife sobre las familias cuya pareja parental es del mismo sexo. Se entrevistó a treinta profesoras. Los datos fueron sometidos a análisis de contenido. Resultó en dos temas: (a) La representación de las maestras acerca de las familias cuya pareja parental es del mismo sexo; (b) Sus percepciones de los niños que viven en este tipo de familias. Prevaleció un discurso que considera que este tipo de familia no es "normal", pero aun así, hay que respetarla. En cuanto a los niños, la mayoría de las maestras declararon que sufren o pueden sufrir consecuencias adversas, como ser víctimas de prejuicios y tener problemas con la orientación sexual futura. Aunque una minoría, hay maestras que no ven razón por la que estos niños sufren daños diferentes de los que pueda sufrir por los demás que viven en entornos familiares tradicionales.

Palabras clave: Maestras de escuelas primarias, representación de la familia, parejas del mismo sexo.

$\mathrm{Na}$ sociedade atual, intensificou-se a visibilidade das mais variadas configurações familiares. Casais constituídos por dois homens ou duas mulheres são muito mais que uma exceção. Melhor dizendo, são sujeitos que buscam sair da clandestinidade e encontrar um lugar social de reconhecimento e legitimação (Barajas, 2012). É bastante provável que a presença de crianças nas escolas originadas dos vínculos entre esses casais torne-se cada vez mais frequente. Neste sentido, é necessário assegurar a legitimidade dessas famílias e o direito dos cidadãos/cidadãs a um relacionamento afetivo livre dos preconceitos e determinações sociais imutáveis. A criança advinda desse tipo de união deverá, igualmente, ter direito a uma educação sem discriminações. Porém pesquisas realizadas envolvendo a escola mostram que ainda é muito forte a representação segundo a qual qualquer modelo de família que escape ao tradicional (pai, mãe e filhos) seria desajustado e disfuncional (Amazonas, Lima, Siqueira, \& Arruda, 2008).
De toda forma, os recentes questionamentos sobre o modelo de família baseado em um casal heterossexual, como única possibilidade, e a despatologização das homossexualidades levaram a modificações na concepção de família. Nesse sentido, vê-se hoje uma disputa entre as diferentes concepções de família, embora, paradoxalmente, esta disputa venha servindo para redobrar o valor atribuído à família tradicional, em menosprezo de outras possibilidades de construção de vínculos afetivo-sexuais que escapem às suas normas e aos seus princípios (Bento, 2012). Nessa perspectiva, diz-nos Lobo (2002):

Não é a família per se que é constitucionalmente protegida, mas o locus indispensável de realização e desenvolvimento da pessoa humana. Sob o ponto de vista do melhor interesse da pessoa, não podem ser protegidas algumas entidades familiares e desprotegidas outras, pois a exclusão refletiria nas pessoas que as integram por opção ou por circunstâncias da vida, comprometendo a 
realização do princípio da dignidade humana. (p. 8)

Como é possível observar, concordemos ou não, a família, mais do que qualquer outro tipo de vínculo afetivo e/ou sexual, é vista como o locus privilegiado de desenvolvimento e proteção dos indivíduos, principalmente das crianças. Desse modo, considera-se de importância fundamental investigar como professores/as que lidam com a população infantil representam famílias constituídas por casais do mesmo sexo.

Tomamos o conceito de representação a partir dos estudos culturais, como o fez Stuart Hall (2000), conectando-o aos conceitos de identidade e diferença. Trata-se de uma representação pós-estruturalista. Nessa perspectiva, "a representação é concebida unicamente em sua dimensão de significante, isto é, como sistema de signos, como pura marca material" (Silva, 2000, p. 90).

Assim, a representação pode expressar-se por meio de filmes, fotografias, desenhos, texto, expressão oral, etc. São descartadas, da representação, toda e qualquer conotação mentalista ou associação com uma suposta interioridade psicológica, pois representar é a maneira como os sistemas apresentam, simbólica e socialmente, as identidades; são modos culturais de atribuir significados que são produzidos em meio a relações de poder (Louro, 2008).

Em outras palavras, são formas de interpretar e de atribuir sentido que se dá em um campo de forças em conflito, movimentado pelas diferenças de perspectivas. Cada representação de família, por exemplo, é apenas uma versão, uma possibilidade entre tantas outras que poderiam ser produzidas. Elas são, no sentido dado por Foucault (1970/1999), discursos que circulam. $\mathrm{O}$ autor entende o discurso como sendo a circulação de verdades sobre algo em determinado tempo histórico, que torna possível falar sobre algo.

. . . o discurso nada mais é do que a reverberação de uma verdade nascendo diante de seus próprios olhos; e, quando tudo pode, enfim, tomar a forma do discurso, quando tudo pode ser dito e o discurso pode ser dito a propósito de tudo, isso se dá porque todas as coisas, tendo manifestado e intercambiado seu sentido, podem voltar à interioridade silenciosa da consciência de si. (Foucault, 1970/1999, p. 49)

Mais ainda, as representações fazem mais do que interpretar/descrever práticas sociais; elas as produzem. Por meio delas, os significados são produzidos e damos sentido à nossa experiência, ao que somos e até ao que podemos vir a ser (Foucault, 1970/1999; Woodward, 2000).

De acordo com Woodward (2000, p. 17) "a representação inclui as práticas de significação e os sistemas simbólicos por meio dos quais os significados são produzidos, posicionando-nos como sujeito". Trata-se de um processo cultural que produz identidades individuais e coletivas e se baseiam em sistemas simbólicos que nos indicam quem somos, quem poderíamos ser, quem queremos ser. É nessa perspectiva que o discurso é, portanto, um conjunto de saberes que vai adquirindo o status de verdades sobre algo. No momento em que entramos em contato com tais verdades, passamos a existir e a agir atravessados pelos sentidos que nos tomam como consciência de si (Fernandes, 2012).

Desse modo, ao investigar a forma como professores/as de Ensino Fundamental representam as uniões entre casais do mesmo sexo e percebem as crianças que vivem nessas famílias, questionam-se as condições que possibilitaram a sua construção e as posições de poder, a partir das quais elas se formaram. Pois essas representações e posições irão repercutir sobre suas performances em sala de aula e estarão imbricadas no processo de subjetivação e individuação das crianças que serão seus alunos.

Ao representar a família em um determinado modelo, não importa qual seja, apagam-se as diferenças entre os vários e singulares agrupamentos familiares, escamoteiam-se suas gradações, suas continuidades e as suas descontinuidades. A diferença, nesses casos, é relegada ao status de mero acessório, de simples acidente (Silva, 2002).

Além disso, sabe-se que a representação nunca é imparcial, pois carrega sempre um índice de valoração: "normal" ou "anormal", "bom" ou "mau", "certo" ou "errado". Assim, acaba 
por produzir a equivocada concepção segundo a qual um modelo de família seria melhor ou pior do que outro. $\mathrm{Na}$ verdade, esse jogo valorativo depende, necessariamente, da perspectiva que se adota.

A escola, enquanto sistema que tem o poder de representar, deve constituir-se em um espaço que possibilite diferentes interpretações, pontos de vista e perspectivas acerca dos temas por ela tratados, visando à preservação da dignidade humana.

Outro aspecto que se deve salientar é que professores são figuras de autoridade e referência para seus alunos, responsáveis por sua formação e pela transmissão de conhecimento que não é neutro, mas produzido em um campo de forças. Quem o produz está em uma posição de poder dizer: é isso, é assim que são as coisas (Foucault, 1970/1999; Silva, 2002).

Nesse embate de forças, os conceitos produzidos podem reduzir o diferente ao igual. Ao representar a família em um único e hegemônico modelo - o nuclear e heteronormativo - por exemplo, a escola acaba por reunir todos os indivíduos em uma única classe, à medida em que busca as semelhanças entre os diferentes, numa tentativa incessante de classificação. Ora, sabe-se que a hetoronormatividade (Butler, 2003) é um tipo de discurso que imprime como verdade natural a ideia de que as organizações afetivo-sexuais não heterossexuais são anormais ou desviantes, produzindo pares de opostos que fomentam a hierarquização e a exclusão. Diante desse quadro, a proposta deste trabalho é investigar como professores/as de Ensino Fundamental de escolas particulares, da zona centro da cidade do Recife, representam as famílias resultantes de uniões entre pessoas do mesmo sexo. Para tanto, interroga-se o que pensam e como se sentem em relação a elas; os valores e preconceitos que lhe são atribuídos; como percebem as crianças que vivem em famílias, cujos pais são homossexuais.

Nossa expectativa é contribuir para problematizar as "verdades" que são produzidas no espaço escolar e que estão influenciando as condições de inclusão ou exclusão social. Partimos do princípio de que o discurso em si mesmo não é libertador, nem opressivo. Pois, ele é uma das formas de articulação do saber-poder que operacionaliza certos jogos de verdade, criando as possibilidades de criação de sujeitos normatizados (Foucault, 1978/2010). Mas, por serem forças em constante tensão, possibilita também a resistência e a libertação. Assim, para além da simples sujeição, a investigação das condições históricas promoveria a compreensão do surgimento desse discurso e não outro (Fernandes, 2012; Moraes, 2010).

\section{Metodologia}

\section{Participantes}

A cidade do Recife está mapeada por Regiões Político-Administrativas (RPAs), que se dividem em seis zonas: RPA1 Centro; RPA2 Norte; RPA3 Noroeste; RPA4 Oeste; RPA5 Sudoeste; RPA6 Sul (Prefeitura da Cidade do Recife, 1997). Esta pesquisa foi realizada na Zona Centro da cidade do Recife (RPA1).

Inicialmente, foi realizado o levantamento do número de escolas existentes nesta zona que ofereciam o Ensino Fundamental. Em seguida, foram sorteadas $10 \%$ das escolas públicas e $10 \%$ das escolas particulares existentes na zona, para compor a amostra.

Em cada escola sorteada, foi pedida a autorização para a realização da pesquisa. Depois de obtida a permissão das escolas, fez-se um levantamento de todos os professores/as de cada escola que atuavam no Ensino Fundamental e foram sorteados/as $10 \%$ do total. Em seguida, agendou-se um encontro no qual foram explicados os objetivos da pesquisa, apresentado o Termo de Consentimento Livre e Esclarecido (TCLE) e, somente após sua assinatura, foi iniciada a Produção dos Dados.

Embora o critério de inclusão dos participantes abrangesse os dois sexos, não foram encontrados indivíduos do sexo masculino atuando como professores nessas escolas.

Assim, foram entrevistadas 30 professoras, sendo 18 de escolas particulares e 12 de escolas públicas. A faixa etária variou de 25 a 48 anos de idade para as professoras das escolas particulares, e 40 a 59 anos para as professoras das escolas públicas. 
Apesar dos cuidados adotados na escolha da amostra, não se pode dizer que se trata de uma amostra significativa, nem que ela represente a população de professores do Ensino Fundamental da Cidade do Recife. A escolha por essa zona da cidade se deu pelo critério de conveniência, e nela buscou-se abranger o maior número possível de escolas, considerando-se tanto escolas públicas quanto privadas, assim como o maior número possível de professores em cada uma das escolas sorteadas. No entanto, isso não significa dizer que se pretendeu, nesta pesquisa, adotar uma amostra representativa nem alcançar generalizações.

\section{Instrumento}

Realizou-se entrevista aberta, contendo duas questões: (a) Você já teve alguma experiência, na escola, de lidar com crianças provenientes de famílias em que o casal parental é do mesmo sexo? (b) Como você se sentiu nesta situação? Outros questionamentos emergiram a partir das respostas dadas pelas professoras.

\section{Procedimento de Produção dos Dados}

O projeto foi submetido e aprovado pelo Comitê de Ética da Universidade Católica de Pernambuco (Processo n ${ }^{\circ}$. 25000-050953/200481 , Parecer $\left.n^{\circ} .071 / 2008\right)$. Antes das entrevistas, foi explicado às professoras o objetivo da pesquisa e solicitado que assinassem o Termo de Consentimento Livre e Esclarecido.

As entrevistas ocorreram individualmente $\mathrm{e}$ em ambiente privado. As respostas foram gravadas e, posteriormente, transcritas literalmente.

\section{Procedimento de Tratamento e Análise das Respostas às Entrevistas}

As etapas do tratamento e da análise foram as seguintes:

- Inicialmente as entrevistas foram transcritas literalmente, anotando-se as pausas, risos, lacunas, etc.

- Em seguida, foram lidas e relidas, considerando-se os objetivos da pesquisa e visando a delimitar os temas a serem analisados.
- Após a delimitação dos temas, foi construída uma tabela em que constavam as respostas das professoras relacionadas a cada um dos temas com a finalidade de facilitar a análise.

- A partir daí, realizou-se a análise em torno dos temas, entremeando as respostas das professoras à literatura consultada. Este procedimento não foi linear. A cada etapa, o pesquisador tanto trabalhou o material produzido, quanto teorizou sobre ele, em um movimento constante de ida e volta.

\section{Representação das Professoras Acerca de Famílias Constituídas por Casais do Mesmo Sexo}

A respeito das manifestações da sexualidade na escola e das posições dos professores diante do tema, Leão, Ribeiro e Bedin (2010) dizem que o campo é "dominado pelo desconhecimento, pelo preconceito, o tabu e a discriminação" (p. 37) e que os professores não sabem como lidar com as atitudes e comportamentos sexuais que surgem na sala de aula. Pode-se dizer que isso reflete o quadro que se encontra em nossa pesquisa.

Nas respostas dadas pelas professoras nas entrevistas, quando questionadas acerca de como veem as famílias formadas por casais do mesmo sexo, preconceito e homofobia se mesclam ao discurso de inspiração religiosa. A homofobia refere-se ao conjunto de emoções negativas em relação às pessoas homossexuais ou que assim se identificam (Junqueira, 2007), mas a principal justificativa para a "não aprovação" a esse tipo de união é quase sempre a religião, Deus, pecado. Uma delas diz:

Eu acho ainda um negocio muito esquisito. Muito! Pra mim..., eu realmente..., tá fora realmente, até contra a vontade de Deus. Isso ai é pecado, para o homem, para a mulher. É um ser humano como qualquer outro, mas a situação, eu não aceito não. Não vou nem demonstrar pra criança, pra aquela criança, que eu não tô respeitando. Eu respeito. Agora, eu não aceito, não é? Eu não aprovo. (P.13) 
A noção de pecado associada à sexualidade é uma herança judaico-cristã. O judaísmo enfatizou a prática sexual com fins apenas procriativos, reprovando, tanto o incesto quanto a homossexualidade masculina. Isso estava relacionado ao combate aos cultos pagãos e ao crescimento de seus adeptos. Quanto ao Catolicismo, pode-se dizer que essa associação entre religião e sexualidade vista como pecado é historicamente datada. Foi a partir do século IV que "a Igreja Católica começou a imprimir sua moralidade sexual como doutrina e a ter domínio universal" (Farias \& Maia, 2009, p. 33).

Aliadas ao discurso religioso aparecem contradições, ambiguidades e hesitações entre as concepções que possuem e os comportamentos que dizem adotar. É como se o discurso contemporâneo do respeito às diferenças se impusesse, mesclando-se e tencionando os demais discursos, entre eles, o discurso religioso. Outra professora afirma:

Olhe, essa sua pergunta, ela é assim... pra mim que sou uma pessoa assim..., eu tenho uma doutrina aonde a gente preserva o que Deus quer... a gente vai muito pela Bíblia. Então..., eu posso te dizer que eu não sou uma pessoa que tenho preconceitos, de jeito nenhum. Eu tenho amigos homossexuais, que vão na minha casa, e eu os recebo muito bem, mas eu prefiro seguir, assim, o que a Bíblia me pede que eu faça, obedecer a Deus, que é servir convencionalmente. Homem e mulher. (P.19)

O principal referencial dessas professoras é a religião e, quando o discurso laico se contrapõe ao discurso religioso, os conflitos entre as concepções que possuem sobre esse tipo de união e o modo como "devem" comportar-se diante delas, refletem-se em um discurso entrecortado e entremeado por idas e vindas, avanços e retrocessos, afirmações e negações, permitindo entrever as dificuldades que a temática lhes impõe.

Algumas professoras têm claros seus próprios conflitos e preconceitos, como demonstra a resposta a seguir, mas, para outras, como a P.19, o discurso da aceitação e respeito é tensionado pelo discurso religioso.
"Pra mim é um pouco conflitante porque eu não sou uma pessoa que aceita esse tipo de relacionamento como uma coisa normal. Eu teria que, primeiramente, trabalhar comigo mesma para que evitasse a questão do preconceito" (P.1).

Outro aspecto que se destaca é a naturalização das identidades de gênero, fundamentando-se em uma ordem biológica ou cultural. Ao mesmo tempo, delega-se à escola a função de transmitir para as crianças o que é ser uma mulher ou ser um homem. Uma das professoras, ao falar sobre o papel da escola na educação das crianças, diz:

Assim... as diferenças, elas observam no lidar em sala de aula, tanto de um homem como de uma mulher. Assim, as diferenças de sexo. Geralmente eles percebem assim, porque o homem tem um tom mais, é, vamos dizer assim, sério. E a mulher, ela já é mais carinhosa, mais mãe, ela coloca esse lado mais afetivo. Então assim, eu acho que ela, através da escola, dá pra perceber que os sexos, eles podem ser bem definidos: mulher mais feminina e o homem mais masculino, no lidar mesmo, na escola, com o professor e a professora, no caso. (P.20)

Desse modo, a escola vai atuando na construção da diferença entre os sexos, fazendo parecer que elas são naturais. Segundo Butler (2003), nem o sexo nem o gênero seriam construções naturais, mais possibilidades instituídas a partir dos variados discursos circulantes, e que se tornariam possíveis em função dos jogos de verdade historicamente atuantes. Como exemplo da constituição do referencial de gênero na modernidade, temos a heteronormatividade. Outro aspecto destacado pela autora é que a lógica heteronormativa, também institui uma linearidade necessária entre o sexo, o gênero e a orientação sexual. Se uma pessoa nasce com um pênis, logo deve ser homem e direcionar sua sexualidade para uma mulher. Isso seria a ordem natural das coisas. Tudo o que se distancia deste modelo é visto como capaz de causar malefícios ou é patologizado.

Olha, eu não acho graça [risos]. Eu não sei, eu sou hétero, eu gosto de homem. Eu acho 
que tem... eu particularmente não acho... Eu nunca passei por essa situação, né? Eu acho que ninguém pode dizer assim, o que é realmente o que você nunca passou. Mas... é... Mas... Eu, pela minha visão, eu acho que é... eu acho que seria sem graça. Eu já tô apaixonada por um homem, agora, eu não sei as coisas de cada um, porque eu acho que cada um quer o melhor pra si, né? Deus nos fez com livre arbitrio pra gente escolher aquilo que a gente acha melhor pra gente. Só que eu acho que traz consequências que não são legais. Eu, particularmente, acho que é uma relação assim... E com filhos, eu acho que traz consequências pras crianças que não são legais. (P.30)

Segundo Borges e Meyer (2008, p. 63), a escola e os professores compõem "um território em que se constituem e se reproduzem mecanismos homofóbicos". Nesse contexto, os discursos escamoteiam relações de poder que determinam quais identidades sexuais devem ser consideradas legítimas e quem está devidamente autorizado a legitimá-las. Assim, às identidades homossexuais, enquanto vistas como desviantes, lhes é negado, inclusive, o direito a constituir vínculos afetivos conjugais e/ou parentais. Essas famílias sempre são vistas como um território de risco para as crianças e, ainda que tais riscos não estejam manifestos, desconfia-se que eles existam. . . Um, por exemplo, eu vim descobrir no final do ano, que a mãe dele tinha um relacionamento com outra mulher. Ele não apresentava nenhum tipo de problemas por conta disso, mas eu não sei..., eu não sei na vida dele em casa..., eu não sei o que passa na cabecinha dele. Talvez ele se sente bem assim, deixou passar. Pra gente tava tudo tranquilo, mas será que tava mesmo? Será que realmente ele aceitava 100\%? (P.19)

Admitir a possibilidade de uma família formada por casais de pessoas do mesmo sexo com a presença de crianças ameaça o modelo heterossexual de família hegemônico e coloca em risco os próprios alicerces da sociedade (Mello, 2005). Isso porque, a priori, não se admite que as uniões homossexuais possam vir a ser incorporadas ao estatuto de família, pois amor e sexualidade são vistos como direitos restritos "ao universo do casamento monogâmico, indissolúvel e reprodutivo, centrado na complementaridade dos sexos" (p. 177).

Borrillo (2009, citado por Caterina Rea, 2011, pp. 99-100) afirma:

Se a homoparentalidade ainda é percebida como perigosa, é porque faz fracassar o modelo "naturalista" e porque radicaliza a dimensão cultural das regras que governam a filiação, as quais têm sido sempre, na sociedade laica, independentes das leis biológicas, das invariantes antropológicas ou dos princípios psicanalíticos ${ }^{2}$.

Essas questões de homofobia e preconceito já vêm sendo referendadas por outras pesquisas, tais como a desenvolvida por Farias e Maia (2009), na qual foram entrevistados psicólogos jurídicos a respeito da possibilidade de adoção por homossexuais. Os resultados desta pesquisa apontam que a questão do preconceito é recorrente nas falas desses profissionais. Há uma concepção de que, tanto o casal homossexual, quanto a criança a ser adotada poderão enfrentar frequentes situações de preconceito nas relações sociais cotidianas, e isso vai demandar deles condições emocionais especiais para fazer frente a tais situações. Tal reflexão se vê presente na fala de outra entrevistada:

"Eu teria muito cuidado porque eu acho que na sociedade que a gente vive ainda é muito dificil viver numa família assim. Ainda é muito complicado" (P.2).

Outro elemento que se destaca nas respostas das professoras é o discurso da estranheza em torno de um casal do mesmo sexo.

Por mais que a gente ache normal, não é, é uma coisa diferente. E o diferente é estranho, nos inquieta. Mas a gente tentou assim, através de estudos, agir naturalmente, né?

2 Tradução nossa. Texto original: Si la homoparentalidad es aún percibida como peligrosa, es porque hace fracasar el modelo "naturalista" y porque radicaliza la dimensión cultural de las reglas que gobiernan la filiación, las cuales han siempre sido, en la sociedad laica, independientes de las leyes biológicas, de las invariantes antropológicas o de los principios psicoanaliticos. 
Porque antes de serem homossexuais, são pessoas. E trabalhar com pessoas, a gente vê o lado emocional o tempo todo. Eu acredito que não haveria mal nenhum. O mal que eles poderiam fazer é a eles mesmos (P.12).

Nessa perspectiva, o normal é apenas aquilo que é idêntico a nós mesmos. A tendência é tomar a nós mesmos como referência, como a norma, como o ponto original relativamente ao qual se define a diferença. Desse modo, a diferença é vista como uma ameaça à identidade, pois aquilo que está "fora" também nos constitui (Silva, 2000).

Butler (2012, p. 26) diz: "Daí que é insuficiente sustentar que os sujeitos humanos são construções, pois a construção do 'humano' é uma operação diferencial que produz o mais ou menos 'humano', o inumano, o humanamente inconcebível."." As construções do humano produzem um lugar dos excluídos o qual limita o humano e assombra suas fronteiras e, neste caso, aquilo que está fora, perturba e pode ser rearticulado.

Como vemos, os discursos são variados, embora haja o predomínio de uma visão que faz referências reiteradas à diferença e a não normalidade. Há alguns, porém, que apontam a diferença, privilegiando e positivando casais gays. Assim, afirma uma das professoras:

Às vezes eu achava até que eles eram mais compreensivos do que outros pais. No caso, eram dois homens né? E era um menino que era superagressivo. Já tinha outras histórias anteriores, da familia, bastante sofrido e eles resolveram ficar com esse menino. Eu achei até que eles tinham mais atenção do que os outros pais, que eram casais normais. Procuravam saber mais sobre o filho na escola do que os outros pais. (P.26)

3 Tradução nossa. Texto original: De ahi que sea insuficiente sostener que los sujetos humanos son construcciones, pues la construcción de lo 'humano' es una operación diferencial que produce lo más o menos 'humano', lo inhumano, lo humanamente inconcebible.
Para Garcia et al. (2007), na tentativa de serem legalmente reconhecidas, essas famílias, paradoxalmente, tendem a tomar a família nuclear como modelo e a preocupar-se com eventuais falhas na educação das crianças, entre as quais se destacam as dificuldades escolares e os adoecimentos dos filhos. Dizem esses autores:

Este tipo de estruturação familiar é favorecido pelo medo em relação às acusações presumidas no que diz respeito ao cuidado dos filhos: ... parecem ter uma preocupação em cuidar de seus filhos de forma exemplar, para se defender de eventuais críticas em relação ao fato de formarem uma família homoparental. (pp. 284-296)

Quando se trata do reconhecimento da família constituída por casais do mesmo sexo, principalmente em relação aos filhos no processo de escolarização, não é raro encontrar certos discursos que mostram uma discrição por parte desses casais. Tal discrição, muitas vezes, é autoimposta diante da própria homossexualidade, a qual serve como estratégia de evitar discriminação e, com tal postura, tem-se também a intenção de evitar discriminação em relação ao filho. É o que podemos perceber nessa fala:

A gente não desconfiava não, foi uma coisa de repente, ela era casada, bem casada, $e$ de repente, quando a menina saiu da escola, foi que nós ficamos sabendo, entendeu? Que a mãe tinha se separado, ele já era padrasto da menina, e ela tava com uma amiga. (P.27)

Segundo Louro (2008), hoje, quando se trata dos gêneros e da sexualidade, o desafio não é mais aceitar que as posições se tenham multiplicado e que não é mais possível pensá-las a partir de esquemas binários (masculino/feminino, homem/mulher, heterossexual/homossexual), mas sim "admitir que as fronteiras sexuais e de gênero vêm sendo constantemente atravessadas" (p. 21), e mais complicado ainda é admitir que alguns sujeitos habitam, justamente, a fronteira.

A mesma entrevistada ainda diz:

Eu acho que cada um deve procurar ser feliz do modo que quiser. Não é? Pela paixão, se está bem com uma mulher, o que é que 
impede? Não sou contra não. Eu sou dessas que a pessoa tem que procurar ser feliz do modo que tiver vontade, tiver a fim. $O$ que é que adianta tá com um homem e não ser feliz, ser espancada, o homem lhe bater, lhe maltratar? Ai encontra uma pessoa do mesmo sexo que vai lhe dar carinho, lhe dar amor. Ela vai escolher o que? Do mesmo sexo. (P.27)

A fala dessa entrevistada parece representar um locus de resistência em relação ao entendimento comum sobre a sexualidade. Ela consegue compreender que a possibilidade de felicidade ultrapassa os limites do gênero, do que é socialmente aceito e ditado em relação ao sexo. Por outro lado, caracteriza o homem como violento, o que poderia justificar a procura por uma relação homossexual, como compensação.

\section{Como as Professoras Representam as Crianças que Vivem neste Tipo de Família}

Mais uma vez, o discurso que emerge das respostas das professoras é ambíguo. Há uma "preocupação" em afirmar um comportamento de respeito às diferenças, de "normalidade", ao mesmo tempo em que se acentua a dificuldade dos "outros" (nunca de si mesmos) de conviver com essa realidade. Acerca de como lidaria com essa situação em sala de aula, uma das participantes afirma:

"Eu agiria normal. Agora, assim..., as outras crianças, não é? Eu teria que conversar com elas porque elas não iam entender" (P.28).

A participante, a seguir, tenta refletir sobre a temática, assume uma posição de quem questiona o que seria normal e o que seria anormal, porém fica confusa e compara as limitações de crianças advindas dessas famílias, com crianças com necessidades especiais. De todo modo, parece que a situação da pesquisa a faz refletir e propõe que a escola deve ter uma atitude de acolhimento em relação a essas crianças.

Eu acredito que da mesma forma que se comporta com os ditos normais, da mesma forma como as crianças especiais, especiais em quê? Ela tem as limitações dela, é... En- tão todos são especiais, então todos têm as suas limitações, então por que não acolher esse tipo de família? Eu acredito que para muitos tem o choque, né? Eu acredito que para os pais deva ter choque, né? Mas em questão de escola, eu acredito que não. Eu acredito que eles iam acolher normal, como qualquer outra familia. (P.5)

$\mathrm{O}$ que parece, a princípio, um movimento de resistência ao discurso hegemônico do lugar determinado aos diferentes (os não heterossexuais), faz transparecer a dificuldade de "pensar" fora do estabelecido pelo processo de sujeição (sujeito), mesmo que uma aparente torção nos valores pareça ser um discurso diferente. Chamar de "especial", que na história tentou substituir a ideia de deficiente, sugere a necessidade de acolhimento do diferente e, ao mesmo tempo em que inclui, também promove um movimento de exclusão, pois marca essas pessoas pela diferença, e nessa diferença evidenciada pela deficiência ou anormalidade.

De acordo com Quartiero e Nardi (2011, p. 709), "O sistema de ensino tem proposto um olhar para as identidades como um lugar fixo para os sujeitos". Ao mesmo tempo em que uma política de afirmação de certos grupos pela identidade destaca e evidencia a sua existência, trazendo afirmações e conquistas, ele também pode apenas ressaltar as diferenças e marcar mais ainda a sua "natureza" anormal ou desviante da norma. Assim, discutir a diversidade sexual, no âmbito da Educação, torna-se um grande desafio.

A fala seguinte aponta para as dificuldades e as limitações que as professoras demonstram em relação ao tema da sexualidade quando essa tem que ser pensada para além do aspecto puramente biológico e reprodutivo, levando em consideração os aspectos social e político. Parece haver um acordo tácito em relação aos problemas de família que reverberam na escola, e, mais especificamente, nas professoras. Problemas esses já catalogados e conhecidos dos docentes:

Ela sofria, o rendimento dela era muito baixo, a autoestima dela era baixíssima. Porque nós temos problemas sérios tanto a prefeitura, o Estado nessa... nesse... nós 
professores nós temos problemas sérios de familia. Famílias totalmente desestruturadas, mas assim, o preconceito ainda é muito forte, pra se ter uma família homossexual.

Arán (2009) afirma que a capacidade de cuidar de uma criança não pode estar vinculada à orientação sexual de seus pais. Segundo Farias e Maia (2009), pesquisas realizadas sobre crianças que vivem nesse tipo de família têm demonstrado que elas não se diferenciam, em nenhum aspecto significativo, das crianças cujos pais são heterossexuais.

Essas mesmas autoras acrescentam que nem o desenvolvimento emocional nem o estabelecimento de vínculos afetivos parecem ser prejudicados pelo convívio com dois pais ou duas mães.

Tal afirmação pode ser percebida na fala de outra professora, quando ela diz:

Partindo do princípio de que nós vemos a criança como centro de tudo, eu não percebi nenhum... não percebi algo diferente que eu pudesse dar uma atenção maior. . . . A criança não tinha problema nenhum quanto a isso [referindo-se à sexualidade da criança]. (P.15)

A fala dessa professora revela um exercício comum da prática docente, no qual o mecanismo de poder que o integra foi e é a vigilância, no sentido de prevenir as condutas não desejadas. A sexualidade, então, constitui-se como alvo privilegiado da vigilância e controle das sociedades. Multiplicam-se e diversificam-se as formas de regulação, as instâncias e as instituições que the ditam normas (Louro, 2008).

$\mathrm{Na}$ esteira dessa reflexão, vale salientar que, no que tange à identidade e à diferença, trata-se de uma relação social que está sujeita a vetores de forças, em uma constante relação de poder, que é permeada por conflitos e contradições advindas das diferentes posições que os envolvidos assumem. Nesse sentido, muitas vezes aquele que produz o discurso é convocado a ratificar seu discurso, é o que se percebe na fala desta outra participante:

"Na minha turma tinha um menino, todo mundo dizia: 'tia, ele é bicha'..., ele de- monstra mesmo... pelo jeito dele agir, pelo jeito de falar, ele sentia medo de se aproximar pra brincar com os meninos" (P.13).

É interessante salientar aqui o que diz Goellner (2003, p. 29): "O corpo é também o que dele se diz e aqui estou a afirmar que o corpo é construído, também, pela linguagem". Isso significa que a linguagem não apenas reflete a realidade, mas cria aquilo que existe. Quando se trata do corpo, ". . . a linguagem tem o poder de nomeá-lo, classificá-lo, definir-lhe normalidades e anormalidades, instituir" (Goellner, p. 29).

Uma participante, quando questionada sobre se já teve alguma experiência, na escola, no lidar com crianças que viviam em famílias constituídas por um casal do mesmo sexo, afirma que sim e diz como se sentiu:

Eu acho isso uma coisa assim... tão normal, porque é como eu digo na minha história [refere-se à história que contou sobre o desenho], as pessoas para serem felizes, para viverem em harmonia, em respeito, em união, não precisam ter aquela figura paterna, a figura materna, não. Eu não sei se isso mexe com a cabeça da criança, entendeu? Com a minha, porém, como eu sou adulta, não mexe nada. Poderia ser um casal gay masculino ou um casal gay feminino criando uma criança, desde que essa criança se sinta bem, que essa criança seja respeitada e amada. Não vejo por que não ser. (P.23)

Ainda uma terceira participante afirma, a respeito da mesma questão:

"Não vejo diferença nenhuma, obstáculo nenhum. Se a criança não apresentava nenhum problema, falava numa boa, era uma criança saudável, tinha um bom aproveitamento escolar, não tinha complicação nenhuma" (P.22).

A forma como as professoras percebem a questão da sexualidade e a maneira pela qual ela produz e reproduz as identidades e as diferenças, a normatividade heterossexual, parece também "(re)velar" a sua própria construção, enquanto sujeito. Mas não apenas isso: diz e revela também que a maneira de perceberem as crianças advindas de casais do mesmo sexo os coloca em 
uma encruzilhada ética em relação à visão de criança, aluno, sexualidade, identidade, etc. $\mathrm{O}$ se posicionar de um jeito ou de outro parece ser uma maneira de se defender da reflexão que tal situação convoca.

\section{Considerações Finais}

Dois temas foram analisados nesta pesquisa: (a) a representação dos professores acerca de famílias constituídas por casais do mesmo sexo, e (b) como eles percebem as crianças que vivem neste tipo de família.

Em relação ao primeiro tema, pode-se dizer que há uma predominância do discurso que oscila entre: (a) admitir que este tipo de família não é "normal", isto é, as professoras se regem pela norma heteronormativa para referendar o que deve ser uma família, e (b) a afirmação de que, apesar de esse tipo de união não poder ser considerada normal, é preciso respeitá-la. Neste cenário, o preconceito é sempre atribuído ao outro, isto é, à sociedade, aos pais dos alunos, e tantos outros.

Quanto ao segundo tema, repete-se a mesma visão, porém de modo mais enfático. A maioria das professoras considera que crianças que vivem nesta modalidade de família sofrem ou podem sofrer consequências nefastas: preconceitos na escola, na vizinhança, por exemplo. Além disso, temem que elas percebam os pais de forma distorcida. Além do receio de implicações negativas em seu desenvolvimento emocional e social. Dois pais? Duas mães? Aparecem, também, com frequência, temores acerca da futura orientação sexual dessas crianças.

Conforme se discutiu no início do artigo, a lógica parece estar firmemente alicerçada no biológico como determinante do psíquico e do social. Se há um desvio da norma, neste caso a heteronormatividade, o temor do surgimento de "patologias" aparece, e parece nortear as diretrizes na atuação das professoras e do sistema de ensino.

Embora sejam minoritárias, existem exceções a este discurso. Há professoras que estão atentas às mudanças que têm ocorrido na socie- dade e na família nos últimos anos e veem essas transformações como situações comuns aos humanos e que não há razão para que elas provoquem danos às crianças, diferentes daqueles que podem ser sofridos por elas em famílias de configurações tradicionais.

$\mathrm{Na}$ verdade, os discursos dessas professoras apontam, frequentemente, uma tensão entre as mudanças sociais que elas presenciam e antigos (pre)conceitos do que é ou deveria ser uma família e o que é saudável para uma criança.

Nesse sentido, pode-se ver a ação de vigilância a que o sistema educacional se presta, e que parece também operar como um dos elementos que subjetivam essas professoras como instrumentos de patrulha e normatização dos ditos comportamentos desviantes. A escola é um lugar de reprodução do estabelecido ou uma possibilidade de abertura para o novo?

Por fim, podemos dizer que hoje já encontramos uma razoável literatura, tratando do tema da homossexualidade na escola. Essa literatura aponta que a escola é um lugar privilegiado de construção da cidadania e de atitudes de respeito aos direitos do cidadão, não importando nem a raça, nem a religião, nem a orientação sexual, entre outras diferenças.

Apesar disso, a realidade que se encontra nessa instituição não parece ter sofrido grandes modificações nas últimas décadas. Quando se trata de sexualidade, elas se regem pela heteronormatividade. Situações de homofobia, quer sejam explícitas como a violência física, quer simbólicas, através do uso da linguagem, são frequentes no cotidiano, tanto por parte de alunos, como professores, ou ainda de outros profissionais da educação. Como vimos, na revisão da literatura, até mesmo o material didático trabalhado nas escolas exclui a diversidade sexual de seu conteúdo, numa demonstração homofóbica que ignora a existência dessas pessoas.

As questões discutidas neste artigo não se prestam a ser generalizadas e tornadas universais, mas podem apontar a necessidade de que temas, como sexualidade e gênero, sejam abordados com maior profundidade no momento de formação e reciclagem destes profissionais de 
ensino, já que, como discutidos, são eles elementos-chave na formação de cidadãos e de uma nova ética possível da diferença.

Estudos futuros poderiam construir pesquisas interventivas, fazendo com que o caráter de produção de conhecimento da pesquisa acadêmica possa desenvolver-se também no sentido mais político, colocando em discussão questões atuais, possibilitando que família de casais do mesmo sexo e seus filhos não sejam desconsideradas, pois constituem realidade inegável e farão parte dos repertórios subjetivantes de nossa sociedade, postos como possibilidades ao longo da construção das identidades e orientações sexuais de indivíduos.

\section{Referências}

Amazonas, M. C. L. A., Lima, A. O., Siqueira, D. F. C. C., \& Arruda, G. F. (2008). Representação de família e material didático. Revista Interamericana de Psicologia, 42(2), 236-246.

Arán, M. (2009). A psicanálise e o dispositivo diferença sexual. Revista Estudos Feministas (Florianópolis), 17(3), 653-673. doi:10.1590/S0104026X2009000300002

Barajas, K. B. B. (2012). Las familias mexicanas: de la institución al movimento. Trayectorias, significados e imaginários en la configuración de la diversidad familiar. Sociedade e Cultura, 15(2), 297-308.

Bento, B. (2012). As famílias que habitam "a família”. Sociedade e Cultura, 15(2), 275-283.

Borges, Z. N., \& Meyer, D. E. (2008). Limites e possibilidades de uma ação educativa na redução da vulnerabilidade à violência e à homofobia. Ensaio: Avaliação e Politicas Públicas em Educação, 16(58), 59-76. doi:10.1590/S010440362008000100005

Butler, J. (2003). Problemas de gênero: Feminismo e subversão da identidade. Rio de Janeiro, RJ: Civilização Brasileira.

Butler, J. (2012). Cuerpos que importan: sobre os limites materiales y discursivos del "sexo". Buenos Aires, Argentina: Paidós.

Farias, M. O., \& Maia, A. C. B. (2009). Adoção por homossexuais: A família homoparental sob o olhar da psicologia jurídica. Curitiba PR: Juruá.
Fernandes, C. A. (2012). Discurso e sujeito em Michel Foucault. São Paulo, SP: Intermeios.

Foucault, M. (1999). A ordem do discurso (5. ed.). São Paulo, SP: Loyola. (Original publicado em 1970)

Foucault, M. (2010). Mesa redonda em 20 de Maio de 1978. In M. Foucault \& M. B. Motta (Eds.), Ditos \& Escritos IV: Estratégia, poder-saber (2. ed., pp. 335-351). Rio de Janeiro, RJ: Forense Universitária. (Original publicado em 1978)

Garcia, M. R. V., Wolf, A. G., Oliveira, E. V., Souza, J. T. F., Gonçalves, L. O., \& Oliveira, M. (2007). "Não podemos falhar": A busca pela normalidade em famílias homoparentais. In M. P. Grossi, A. P. Uziel, \& L. Mello (Eds.), Conjugalidade, parentalidade e identidades lésbicas, gays e travestis (pp. 277-297). Rio de Janeiro, RJ: Garamond.

Goellner, S. V. (2003). A produção cultural do corpo. In G. L. Louro, J. F. Neckel, \& S. V. Goellner, Corpo, gênero e sexualidade: Um debate contemporâneo na educação (pp. 28-40). Petrópolis, RJ: Vozes.

Hall, S. (2000). Quem precisa da identidade? In T. T. da Silva (Ed.), Identidade e diferença: A perspectiva dos estudos culturais (pp. 103-133). Petrópolis, RJ: Vozes.

Junqueira, R. D. (2007). Homofobia: Limites e possibilidades de um conceito em meio a disputas. Revista Bagoas: Estudos Gays: Gêneros e Sexualidades, 1(1), 1-22.

Leão, A. M. de C., Ribeiro, P. R. M., \& Bedin, R. C. (2010). Sexualidade e orientação sexual na escola em foco: Algumas reflexões sobre a formação de professores. Revista Linhas (Florianópolis), 11(1), 36-52.

Lobo, P. L. N. (2002). Entidades familiares constitucionalizadas: Para além do numerus clausus. Mundo Jurídico. Recuperado em http://www. mundojuridico.adv.br

Louro, G. L. (2008). Gênero e sexualidade: Pedagogias contemporâneas. Pro-Posições, 19(2), 17 23.

Mello, L. (2005). Novas famílias: Conjugalidade homossexual no Brasil contemporâneo. Rio de Janeiro, RJ: Garamond.

Moraes, A. T. (2010). O discurso em Foucault: Noções para uma prática jornalística. Intercom Sociedade Brasileira de Estudos Interdiscipli- 
nares da Comunicação. Recuperado em http:// www.intercom.org.br/sis/regional/resumos/ R21-0050-1.pdf

Prefeitura da Cidade do Recife. (1997). Perfil dos bairros. Recuperado em http://www2.recife. pe.gov.br/a-cidade/perfil-dos-bairros

Quartiero, E. T., \& Nardi, H. C. (2011). A diversidade sexual na escola: Produção de subjetividade e políticas públicas. Revista Mal-Estar e Subjetividade, 11(2), 701-725.

Rea, C. (2011). Desnaturalización de la sexualidad: última frontera de la democracia. Formas afectivas y parentales a la prueba de la noción de género. Ex aequo, 23, 97-111.

Silva, T. T. (2000). A produção social da identidade e da diferença. In T. T. Silva (Ed.), Identidade e diferença: A perspectiva dos estudos culturais (pp. 73-102). Petrópolis, RJ: Vozes.
Silva, T. T. (2002). O sujeito da educação: Estudos foucaultianos. Petrópolis, RJ: Vozes.

Woodward, K. (2000). Identidade e diferença: Uma introdução teórica e conceitual. In T. T. Silva (Ed.), Identidade e diferença: A perspectiva dos estudos culturais (pp. 7-72). Petrópolis, RJ: Vozes.
Recebido: 05/12/2013

$1^{\mathrm{a}}$ revisão: 06/03/2015

Aceite final: 10/03/2015 